\title{
JUURNAL_RU
}

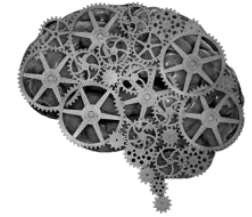

COMPANY GROUP "INTELLEKT"

\author{
Ланская Е.В., Ланская О.В. \\ ФГБОУ ВО «Великолукская государственная академия \\ физической культуры и спорта» \\ Великие Луки, Россия
}

doi: 10.18411/lj2016-3-20

\section{Биоэлектрическая активность мышц при выполнении спортивных движений, специфичных для пауэрлифтинга, баскетбола и легкоатлетического бега}

Введение. Целенаправленная двигательная деятельность имеет принципиально важное значение в адаптации организма человека к различным условиям его жизнедеятельности, поэтому исследование механизмов регуляции движений, обеспечивающих достижение успешного результата, является одной из центральных проблем физиологии. Идеальной моделью для изучения механизмов разнообразных движений служит двигательная деятельность спортсменов. Объективным методом для получения информации о физиологических процессах, происходящих в нервно-мышечном аппарате в процессе реализации специальных двигательных навыков, является электромиография, представляющая собой запись биоэлектрической активности мышц (электромиограмм - ЭМГ), которая в последнее время находит широкое применение в биомеханике, эргономике и спортивных исследованиях [1]. На основе методики ЭМГ изучены особенности регуляции движений в разных видах спорта, включая легкоатлетический бег, спортивные игры, тяжелую атлетику, единоборства, стрельбу из пистолета и др. [1-5]. Однако зачастую исследователи ограничиваются изучением особенностей биоэлектрической активности мышц при реализации движений, специфичных только для какого-то 
определенного вида спорта, поэтому в опубликованных работах отсутствует комплексный ЭМГ анализ деятельности мышц при выполнении спортсменами характерных для различных видов спорта движений, не проводится анализ активности мышц при различных условиях их функционирования. Настоящее исследование и было посвящено изучению этой актуальной для теоретической и практической физиологии проблемы.

Целью исследования являлось изучение параметров ЭМГ скелетных мышц при выполнении спортивных движений, специфичных для пауэрлифтинга, баскетбола и легкоатлетического бега.

Материалы и методы. В исследовании приняли участие спортсмены (все лица мужского пола), занимающиеся пауэрлифтингом (7 человек), баскетболом (5 человек) и легкоатлетическим бегом на короткие дистанции (9 человек). Испытуемые имели спортивную квалификацию от I взрослого разряда до КМС, возраст обследуемых - 17-25 лет. Стаж спортивной деятельности составил от 7 до 12 лет.

Методом исследования являлась поверхностная ЭМГ. Отведение и регистрация биопотенциалов скелетных мышц осуществлялась по общепринятой методике [6-7] с помощью современного 16-ти канального электромиографа «MegaWin ME 6000» (Финляндия, 2008), а обработку полученных данных проводили в специальной компьютерной программе «MegaWin». К исследованию привлекались только испытуемые-правши и ограничивались регистрацией биопотенциалов мышц с правой половины тела. Для регистрации ЭМГ использовались одноразовые накожные электроды с межэлектродным расстоянием 2 см. Перед тем как накладывать электроды на мышцу кожная поверхность очищалась от волосяного покрова и обрабатывалась специальным раствором, чтобы была хорошая проводимость электрического импульса мышцы. Каждый спортсмен, в день его участия в исследовании, был освобожден от тренировок.

Пауэрлифтерам предлагалось выполнить однократный жим штанги лежа 
на горизонтальной скамье. Вес штанги составлял 80\% от индивидуального максимума. ЭМГ регистрировались с передних и средних пучков дельтовидной мышцы, большой мышцы груди, широчайшей мышцы спины, двуглавой и трехглавой мышц плеча. В качестве двигательной модели у баскетболистов был выбран бросок одной рукой от головы (сверху), который спортсмены выполняли с различного расстояния до корзины (со штрафной линии, с дальней, средней и близкой (из-под кольца) дистанции). При выполнении спортивных движений баскетболистами регистрировались ЭМГ двуглавой и трехглавой мышц плеча, лучевого сгибателя и локтевого разгибателя кисти. У легкоатлетов во время преодоления 100-метровой дистанции регистрировались ЭМГ двуглавой и прямой мышц бедра, камбаловидной и передней большеберцовой мышц. У спортсменов изучены следующие параметры ЭМГ мышц: средняя амплитуда ЭМГ, частота потенциалов действия ЭМГ, интегрированная электроактивность ЭМГ исследуемых мышц. Статистическая обработка результатов исследования проводилась с использованием непараметрических критериев Манна-Уитни и Уилкоксона.

Результаты исследования и их обсуждение. В первой серии исследований нами были изучены параметры ЭМГ мышц при выполнении пауэрлифтерами жима штанги лежа на горизонтальной скамье, который является одним из трех соревновательных упражнений силового троеборья (пауэрлифтинга). Оригинальный образец записи ЭМГ тестируемых мышц представлен на рис. 1.

Анализ показал, что при выполнении пауэрлифтерами жима штанги лежа среди всех тестируемых мышц самые высокие показатели амплитуды, интегрированной активности и частоты ЭМГ регистрировались в передних

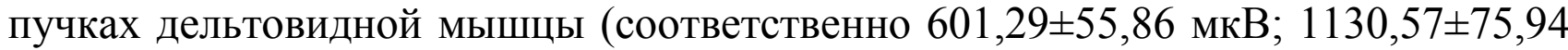

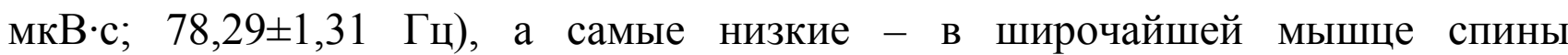

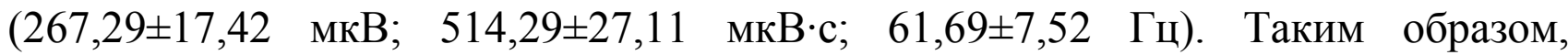
проведенное ЭМГ-исследование показало, что передние пучки дельтовидной 
мышцы являлись «ведущими» при выполнении пауэрлифтерами жима штанги лежа на горизонтальной скамье, что согласуются с результатами исследования [8]. Анализ ЭМГ позволил выявить вариативность в последовательности вовлечения в работу изучаемых мышц. В исходном положении спортсмена, когда он удерживал штангу на вытянутых руках над грудью (маркер 1 на рис. 1), первыми начинали сокращаться передние пучки дельтовидной мышцы, трехглавая мышца плеча и большая грудная мышца, которые, к моменту завершения движения (маркер 2 на рис. 1) дольше всех остальных мышц оставались включенными в работу.

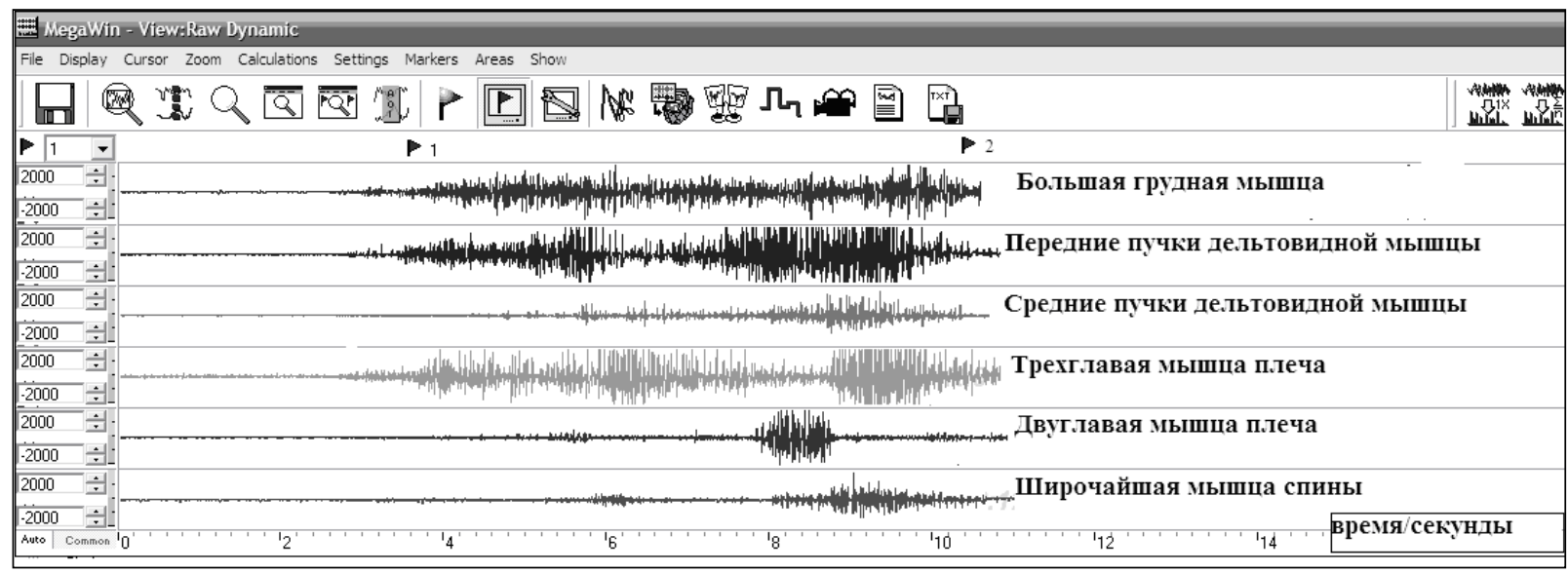

Рис. 1 - Типичный образец записи ЭМГ основных мышц при выполнении жима штанги лежа на горизонтальной скамье.

Примечание к рисунку: маркер 1 - начало выполнения упражнения, маркер 2 - завершение упражнения (в течение временного периода от маркера 1 до маркера 2 спортсмен из исходного положения, при котором штанга удерживалась на вытянутых руках над грудью, опускал штангу на грудь, а затем выжимал штангу от груди до полного выпрямления рук в локтевых суставах).

Далее рассмотрим параметры ЭМГ скелетных мышц при выполнении баскетболистами броска одной рукой от головы (сверху) с различного расстояния до корзины. В результате исследования было установлено, что при выполнении броска со штрафной линии наиболее высокие показатели средней 
амплитуды, интегрированной активности и частоты биопотенциалов регистрировались в лучевом сгибателе кисти (соответственно 147,6 $\pm 6,66$ мкВ; $692,8 \pm 43,84$ мкВ·c; 128,5 $\pm 6,9$ Гц), а самые низкие - в двуглавой мышце плеча

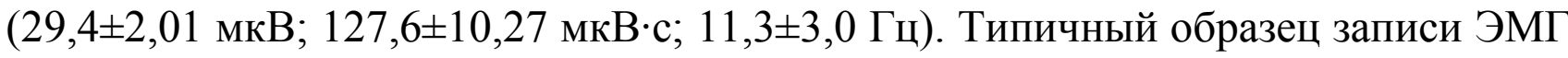
тестируемых мышц при выполнении броска одной рукой от головы (сверху) с линии штрафного броска представлен на рис. 2 (А). Из анализа порядка включения и выключения мышц плеча и предплечья при выполнении штрафного броска следует, что первым из всех активировался лучевой сгибатель кисти (маркер 1 на рис. 2 (А)), который вместе с локтевым разгибателем кисти последними выключались из работы (маркер 2 на рис. 2 (А)).

Выявлено, что при выполнении броска с дальней дистанции самые высокие амплитуда, интегрированная активность и частота биопотенциалов регистрировались в лучевом сгибателе кисти (соответственно 178,6 $\pm 6,35$ мкВ;

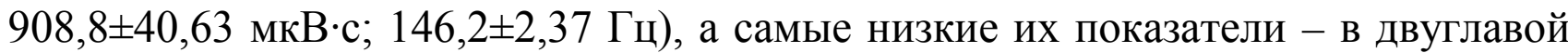

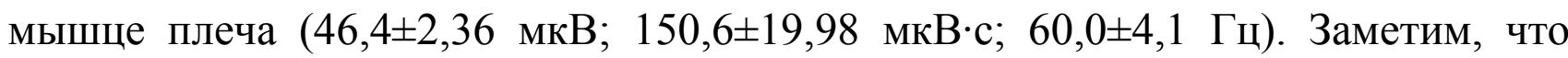
такая же тенденция в показателях наблюдалась и при выполнении штрафного броска. Типичный образец записи ЭМГ тестируемых мышц плеча и предплечья при выполнении броска одной рукой от головы (сверху) с дальней дистанции представлен на рис. 2 (Б). При рассмотрении рис. 2 (Б) можно заметь, что паттерны ЭМГ исследуемых мышц верхней конечности имеют отличительные особенности, которые, например, проявляются в последовательности вовлечения в работу и выключения мышц. Первыми из всех активировались лучевой сгибатель и локтевой разгибатель кисти (маркер 1 на рис. 2 (Б)), которые последними из всех выключались из работы (маркер 2 на рис. 2 (Б)).

В результате анализа ЭМГ параметров, зарегистрированных у баскетболистов при выполнении броска со средней дистанции, была обнаружена тенденция в показателях, практически аналогичная той, которая наблюдалась при выполнении спортсменами броска с дальней дистанции (рис. 2 (В)), поэтому на анализе таких данных мы останавливаться не будем. 

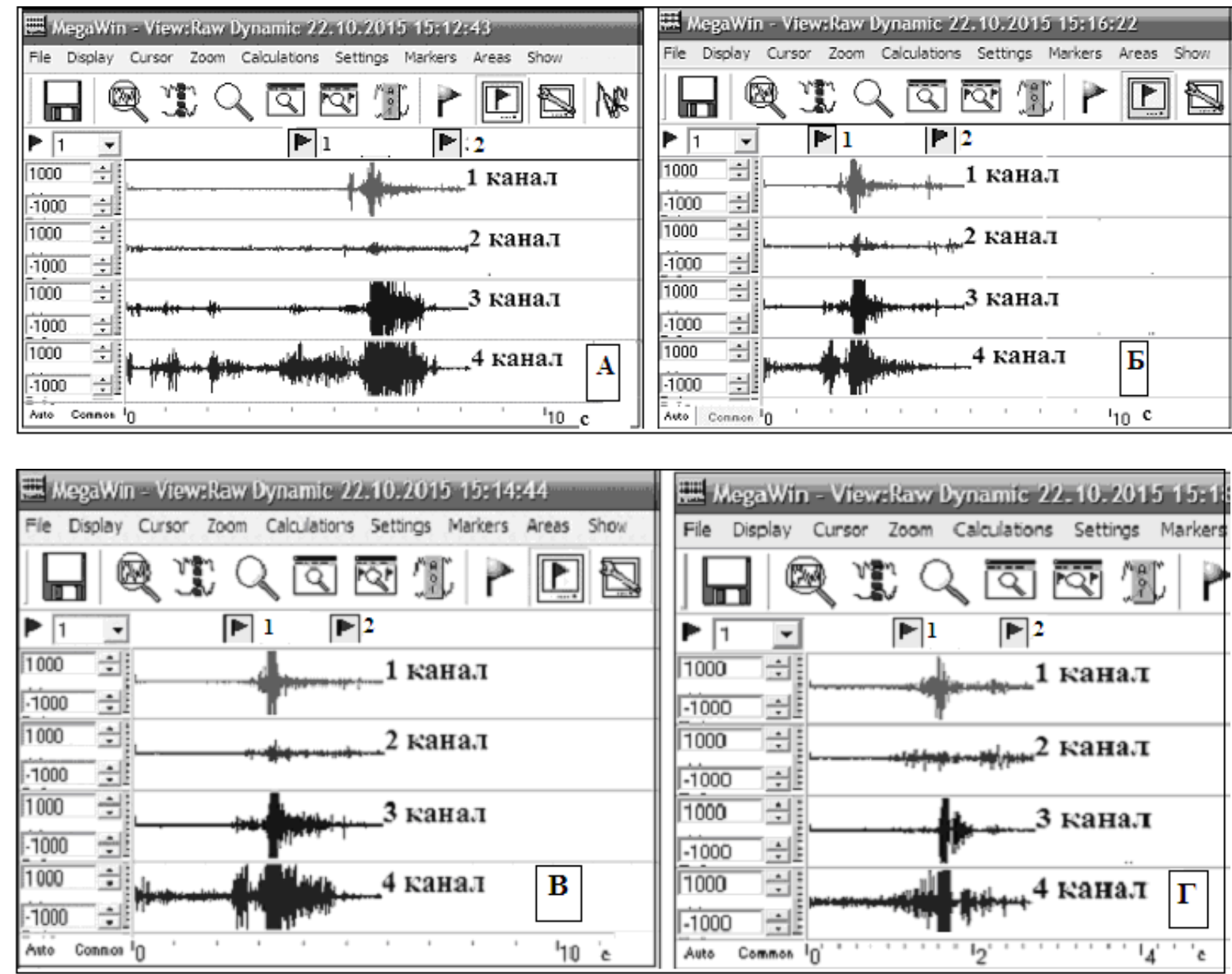

Рис. 2 - Типичный образец записи ЭМГ мышц плеча и предплечья при выполнении броска одной рукой от головы (сверху) с линии штрафного броска (А), с дальней (Б), средней (В) и близкой (Г) дистанции.

Примечания к рис. 2 (А-Г): 1-4 - каналы мышц правой верхней конечности: 1 - трехглавая мышца плеча, 2 - двуглавая мышца плеча, 3 - локтевой разгибатель кисти, 4 - лучевой сгибатель кисти;

маркер 1 - начало выполнения приема, маркер 2 - завершение выполнения приема.

Дальнейший анализ показал, что при выполнении броска с близкой дистанции, также как и при выполнении штрафного броска и броска с дальней и средней дистанции, самые высокие показатели амплитуды, интегрированной активности и частоты биопотенциалов регистрировались в лучевом сгибателе

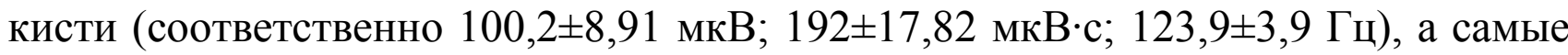

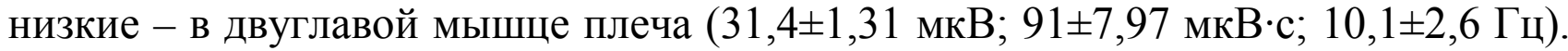
Типичный образец записи ЭМГ тестируемых мышц при выполнении броска 
одной рукой от головы (сверху) с близкой дистанции представлен на рис. 2 (Г), на котором можно видеть не только разный уровень активности мышц плеча и предплечья, но и практически одновременное их вовлечение в работу и выключение из нее.

Таким образом, при выполнении дистанционных бросков лучевой сгибатель кисти является «ведущей» мышцей, и электроактивность этой мышцы (а, значит, и ее нервных центров) в существенной мере определяет реализацию бросков, а локтевой разгибатель кисти и трехглавая мышца плеча являются вспомогательными мышцами при выполнении данного приема с различного расстояния до корзины. Сделанное нами заключение согласуется с литературными данными о том, что ключевое значение для точности бросков определяют именно сгибание кисти и разгибание в локтевом суставе [9], поэтому к группе мышц, определяющей точность бросков, относится комплекс мышечных групп предплечья, реализующих движение кисти, и трехглавая мышца плеча, работа которой осуществляет разгибание в локтевом суставе [5].

В результате исследования также было установлено, что самые высокие показатели средней амплитуды и частоты ЭМГ тестируемых мышц плеча и предплечья в основном регистрировались при выполнении броска с дальней дистанции, а самые низкие - при выполнении броска с близкой дистанции (изпод кольца). Таким образом, при выполнении броска со штрафной линии, а также с дальнего и среднего расстояния до корзины в составе тестируемых мышц верхней конечности рекрутировалось большее количество двигательных единиц (ДЕ), то есть вовлекалось большее количество мышечных волокон и иннервирующих их нервных центров, а также имела место наибольшая частота разрядов ДЕ этих мышц, чем при выполнении броска из-под кольца. Это может объясняться тем, что чем больше дистанция, тем больше должна быть амплитуда движений при замахе и мощнее заключительное усилие при выпуске мяча [10].

Заключительная серия исследований была посвящена регистрации и 
последующему анализу параметров ЭМГ скелетных мышц у легкоатлетов во время спринтерского бега. Типичный образец записи ЭМГ мышц голени и бедра при спринтерском беге представлен на рис. 3.

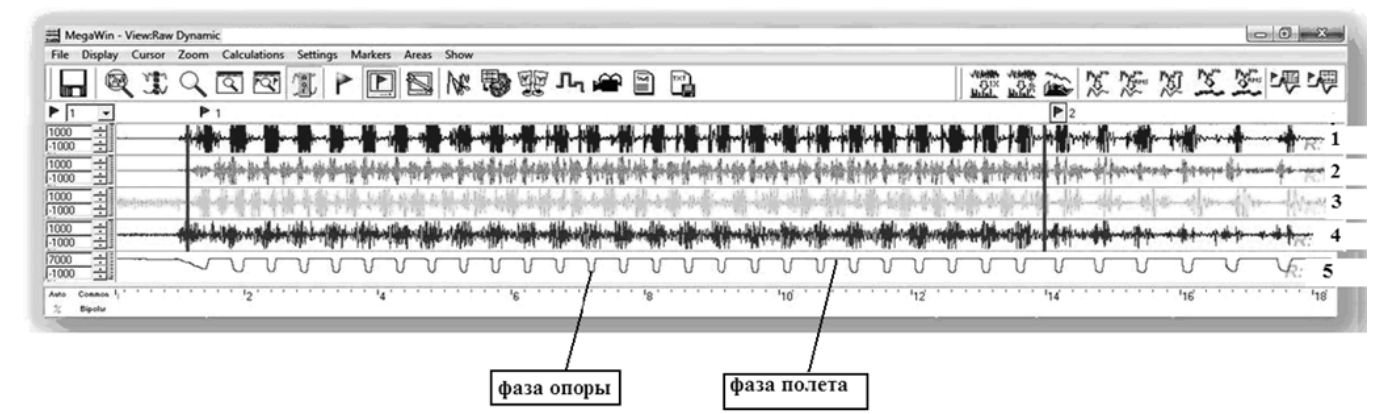

Рис. 3 - Типичный образец записи ЭМГ мышц при спринтерском беге (примечание к рисунку:

1-4 - каналы мышц нижней конечности: 1 - камбаловидная мышца, 2 - передняя большеберцовая мышца, 3 - прямая мышца бедра, 4 - двуглавая мышца бедра; 5 - канал тензодатчика; маркеры: 1- старт, 2 - финиш).

Цикл бегового шага состоит из фазы опоры (амортизация, прохождение проекции вертикали и отталкивание) и фазы полета (движение маховой ноги вперед и опускание ее на опору) [11]. При ЭМГ исследовании мышц бедра и голени во время спринтерского бега было выявлено достаточно четкое чередование высокоамплитудных и одновременно высокочастотных ЭМГ мышц с концентрацией максимумов активности в зависимости от фазы каждого цикла бегового шага. Так, при опоре ноги высокий уровень активности проявляли двуглавая мышца бедра и камбаловидная мышца (с преимуществом на стороне двуглавой мышцы бедра), а значительно более низкий - прямая мышца бедра и камбаловидная мышца. В фазу переноса (полета) ноги наиболее активными мышцами были прямая бедра и передняя большеберцовая (с преимуществом на стороне прямой мышцы бедра), по сравнению с которыми активность двуглавой мышцы бедра была несколько ниже, но несущественно, а самую низкую активность среди всех тестируемых мышц проявляла камбаловидная мышца. Полученные нами данные согласуются с результатами исследований биомеханизмов циклических локомоций во время бега [12]. 
Заключение. При выполнении спортивных движений пауэрлифтерами, баскетболистами и легкоатлетами-бегунами были определены «ведущие» мышцы, специфичность паттернов биоэлектрической активности которых проявлялась в присущих для каждого двигательного навыка характеристиках ЭМГ мышц: амплитуды и частоты потенциалов действия, порядка активации мышц и выключения, интегрированной электрической активности мышц. Характеристики биоэлектрической активности скелетных мышц, обеспечивающие выполнение изучаемых спортивных движений, можно применять при отборе специально-подготовительных упражнений, которые используются в процессе технической и физической подготовки пауэрлифтеров, баскетболистов и легкоатлетов-бегунов.

\section{Литература:}

1. Ципин Л.Л. Методологические аспекты применения электромиографии при изучении спортивных движений разной интенсивности // Ученые записки университета имени П.Ф. Лесгафта. 2015. №8(126). С. 188-193.

2. Прянишникова О.А., Городничев Р.М., Городничева Л.Р., Ткаченко А.В. Спортивная электронейромиография // Теория и практика физической культуры. 2005. № 9. С. 6-12.

3. Пухов А.М., Городничев Р.М. Электромиографические критерии результативности стрельбы из пистолета // Теория и практика физической культуры. 2012. №11. С. 79.

4. Чермит К.Д., Заболотний А.Г., Шаханова А.В., Тхагова А.А. Классификация биоэлектрической активности мышц при выполнении приседания со штангой в пауэрлифтинге // Вестник Адыгейского государственного университета. 2012. Серия 4: Естественноматематические и технические науки. № 1. [Электронный ресурс]. - 
Режим д доступа: http://cyberleninka.ru/article/n/klassifikatsiyabioelektricheskoy-aktivnosti-myshts-pri-vypolnenii-prisedaniya-so-shtangoy-vpauerliftinge

5. Чермит К.Д., Заболотний А.Г., Ельникова О.О., Сидоров В.И. Биоэлектрическая активность мышц в процессе реализации штрафного броска в баскетболе // Вестник Адыгейского государственного университета. 2014. Выпуск 3 (142). С. 124-131.

6. Команцев В.Н., Заболотных В.А. Методические основы клинической электронейромиографии. СПб: Лань, 2001. 218 с.

7. Зенков Л.Р., Ронкин М.А. Функциональная диагностика нервных болезней. М.: МЕДпресс-информ, 2004. 448 с.

8. Стафеев А.И., Биржевая О.А. Физиологические основы и методика развития силы в жиме штанги лежа: методические указания к практическим занятиям для студентов 1-3 курсов для специализации «Атлетическая гимнастика». Ульяновск: УлГТУ, 2012. 34 с.

9. Грошев А.М. Обеспечение надежности бросков мяча в баскетболе: автореф. дис. ... канд. пед. наук. Малаховка, 2005. 23 с.

10. Банников А.М., Силкин В.А., Костюков В.В. Студенческий баскетбол (планирование, организация и проведение тренировочного процесса). Краснодар, 2000. 44 с.

11. Жилкин А.И., Кузьмин В.С., Сидорчук Е.В. Легкая атлетика. М.: Издательский центр «Академия», 2009. 464 с.

12. Селуянов В. Биомеханизмы циклических локомоций (спринтерский бег, велосипедный спорт, конькобежный спорт) // Наука в олимпийском спорте. 2005. № 2. С. 169-181. 